\title{
Educação, economia e o governo Lula
}

\author{
Igor Zanoni Constant Carneiro Leão*
}

\begin{abstract}
RESUMO - O pensamento econômico brasileiro viu o desenvolvimento como um crescimento da produtividade geral da economia, o qual deveria ser alcançado através de políticas agrárias ou da sábia intervenção do Estado que, ajudado pelo capital privado nacional ou estrangeiro, maximizaria nosso uso da capacidade produtiva e fecharia a brecha que historicamente constituiu as sociedades latino-americanas em sociedades duais e heterogêneas. Por sua vez, a educação foi pensada pelos economistas como âncora para soldar a defasagem tecnológica que nos separa dos centros desenvolvidos, bem como qualificação do trabalho para o emprego ou para maior eficiência dos setores informais. Com o passar do tempo o pensamento econômico voltou-se mais fortemente para questões distributivas e sociais e a educação foi vista como peça na constituição de uma sociedade ligada por laços de solidariedade soldados por uma cultura comum. Essas visões ainda mantém sua atualidade no país na medida em que o acelerado desenvolvimento de cem anos, entre 1870 e 1970, digamos, manteve o país como nação dependente, periférica e sem capacidade de internalizar plenamente seus centros de decisão. Nesse sentido, em que pese o crescimento dos primeiros anos do século XXI, persistem heranças neocoloniais que urge serem enfrentadas, e para as quais a educação e as políticas sociais devem encontrar ainda seu melhor lugar.
\end{abstract}

Palavras-chave: Desenvolvimento brasileiro. Políticas sociais. Economia no governo Lula. Tecnologia. Educação.

Neste texto faço algumas observações sobre a relação entre desenvolvimento econômico e educação no Brasil de hoje, mais propriamente sobre o que poderiam ser essas relações. Este tema me é caro como economista e como professor, especialmente em um momento no mundo no qual falar em educação ou pedagogia parece temerário e pensar em rumos alternativos para a economia brasileira também, haja vista as enormes dificuldades do governo Lula para implantar pequenas embora essenciais mudanças na forma de conduzir políticas sociais de base ou alterações na política macroeconômica. Entretanto, como dizia Millôr Fernandes, livre pensar é só pensar. Portanto, pensemos com liberdade.

Inicialmente, faço considerações sobre a inserção internacional da economia brasileira, baseando-me especialmente em Fernando Sarti e Mariano F. Laplane, em: O investimento direto estrangeiro e a internacionalização da economia brasileira nos anos 90 . Pensar a partir dessa inserção é importante uma vez que a economia brasileira teve sua

\footnotetext{
* Doutor em Economia pela UNICAMP. Professor do departamento de Economia pela Universidade Federal do Paraná (UFPR). Endereço eletrônico: igorzaleao@yahoo.com.br.
} 
formação no contexto da formação da economia internacional, de forma sempre dita dependente, tardia e subdesenvolvida. Isso significa que o país, como sempre assinalou a Cepal, é uma economia com um déficit em desenvolvimento tecnológico acompanhado de inúmeros déficits sociais expressos na distribuição de propriedade e de renda, no baixo consumo das massas, na precariedade do Estado de Bem-Estar e na heterogeneidade produtiva e social. Esse panorama convive com uma elite pouco inclinada a corrigir esses problemas, fortemente internacionalizada, bem como com uma população pouco politizada e com pequena massa crítica a cerca dos problemas que atravessa cotidianamente. Some-se ainda o enorme poder dos interesses financeiros, bem como da mídia jornalística e televisiva.

A partir do colapso do Plano Cruzado e especialmente a partir do início dos anos 90 a política macroeconômica não apresentou um formato desenvolvimentista que contemplasse uma política industrial integrada e ampla, e a abertura comercial e financeira foi considerada solução suficiente para retomada do desenvolvimento. Isto ocorreu ao mesmo tempo em que se observou uma aceleração dramática das inovações técnicas, da concentração industrial e da competição entre países na diplomacia econômica mundial. Países recentemente industrializados surgem como grandes potências, como a China e a Índia, e mesmo países menores se destacam econômica e diplomaticamente, como o Irã, a África do Sul e a Venezuela. Nesse contexto, o Brasil abre rapidamente seu comércio, desnacionaliza empresas industriais, abala a face do seu Estado Nacional com as privatizações e a persistência de uma política financeira favorável a ganhos externos e de grandes rentistas internos, ao mesmo tempo em que tenta uma integração regional tímida no Mercosul, tudo isso sem reconstruir um desenvolvimento com nexos sólidos em suas políticas econômicas e sociais.

Nos dois governos Lula, a partir do crescimento internacional, o Brasil usa suas vantagens comparativas herdadas para se posicionar na economia mundial, lentamente melhora a posição do governo no que se refere à sua dívida interna e externa, aumenta o volume das reservas, baixa a taxa de juros e inicia uma política social para as camadas mais pobres da população que não consegue, entretanto, até agora, ganhar maior densidade e alcance. As taxas de crescimento se elevam, mas diversos fatores elevam também a taxa de inflação em um momento de crise e incerteza na economia mundial. O governo enfrenta ainda uma oposição interna bastante rude e tem dificuldades em ampliar o espaço da sua governança, mesmo alterando a equipe que assessora o presidente e mudando a direção de órgãos centrais no planejamento. 
Fernando Sarti e Mariano F. Laplane indicam que a internacionalização da economia brasileira implicou aumento do conteúdo importado da produção local - o que pode refletir em incrementos de produtividade - e não aumentou as exportações na mesma proporção, exatamente ao contrário do que ocorreu em países da Ásia, como a Coréia, ou no México. No Brasil, a internacionalização foi principalmente do mercado doméstico, dado que, embora se tenha no Brasil uma população em grande medida ainda pobre, ela é grande, e pôde ser disputada por empresas estrangeiras inclusive aproveitando a perceptível melhora no índice de Gini no governo Lula.

A internacionalização no Brasil foi dirigida não tanto à construção de ativos novos, mas à aquisição de ativos públicos e privados nacionais, também diferentemente do que ocorreu no caso da internacionalização observada na China. No Brasil, aumentou o passivo externo da economia, bem como a importância do país como consumidor de bens intermediários produzidos em outros países. É verdade que esse processo levou à redução de deficiências na infra-estrutura, principalmente nas telecomunicações, bem como melhorou a competitividade de algumas indústrias como a automobilística, mas, em seu todo, resultou numa estrutura produtiva mais eficiente no plano microeconômico todavia com resultados insatisfatórios no plano macroeconômico, como se pode observar pelo elevado custo em termos de bem-estar e de equidade. Por exemplo, tarifas e preços públicos se elevam muito, o crescimento econômico é instável, beneficia especialmente os mais ricos e que podem pôr fichas no mercado financeiro e assim por diante. A melhoria, em termos de distribuição de renda, deve-se especialmente a políticas como o Bolsa Família, mais do que ao comportamento pouco dinâmico de emprego e renda.

Por outro lado, o Brasil conservou sua inserção tradicional de exportador de produtos primários e produtos intensivos em recursos naturais para os países desenvolvidos e de produtos mais especializados e com maior conteúdo tecnológico para os países da América do Sul. Essa inserção, na verdade, se reforçou nos anos 90, embora se observe ganho tecnológico na produção daqueles produtos de menor valor agregado que sofrem uma grande concorrência no plano internacional. Todavia, como assinalam os autores, "Uma estrutura produtiva como a brasileira, apoiada em um sistema industrial complexo, diversificado e com forte presença de filiais estrangeiras e com um mercado doméstico de grandes dimensões, não seria capaz de capturar as oportunidades oferecidas pela expansão do comércio mundial sem remover dois grandes obstáculos 'sistêmicos' para o aprofundamento da industrialização: a 
deficiente capacidade de gerar inovações e a fragilidade dos mecanismos de financiamento de longo prazo."

Esses dois desafios requerem mais do que mudar preços relativos e submeter os produtores a uma maior pressão competitiva. Implica em formular uma política de desenvolvimento ampla, encontrando mecanismos de coordenação que gerem reações individuais construtivas para a sustentação do crescimento.

Por outro lado, como discute Deisy Ventura no Le Monde Diplomatique Brasil, a efervescência que se observava ainda a pouco nos novos governos sul-americanos e que enfatizavam a integração da região transformou-se em conflitos entre Estados, dificuldades para a vida das empresas e dos cidadãos, especialmente nas regiões de fronteira, crescentes tratados bilaterais com outros países e dificuldade para o avanço das forças progressistas nos governos. No Mercosul, por exemplo, as sete instituições que o constituem desmembram-se em incontáveis grupos ad hoc, comitês, subgrupos, comissões, dificultando seu funcionamento. No caso do Brasil, o Ministério do Exterior predomina sobre os demais, mesmo quando os temas discutidos sejam muito variados. O calendário oficial é confuso, tudo isso resultando em burocracia pouco integracionista. Isso contradiz a opinião pública que é favorável ao bloco, e mesmo o preconceito contra o presidente Chávez não impede a visão de que a Venezuela, no Mercosul, pode significar políticas públicas regionais mais amplas, isto é, não apenas política externa mas o envolvimento setor a setor da política interna. Há muito a fazer também no que tange à participação social, mas é sempre difícil saber onde ir, como ser convidado, o que será discutido e o que significam as propostas no Parlamento do Mercosul, recém criado, para que ele possa ser uma tribuna regional.

Entretanto, também no interior do que move ideologicamente o governo Lula, a participação cidadã, o espaço é problemático. Quase dois milhões de pessoas participam de conselhos e conferências abertas à cidadania nos níveis federal, estadual e municipal, mas pouco tem servido de fato ao aumento da democracia e na redução das desigualdades sociais. Não se sabe como lidar com interesses de grupos, entidades e igrejas cuja identidade coorporativa é colocada com freqüência acima da política pública. Também os representantes do governo são pouco importantes, têm pouca informação e têm pouco poder para falar em nome de quem representa.

Como assinala Ana Cláudia Teixeira também no Le Monde, é necessário criar mecanismos de participação, deliberação e controle social das políticas econômicas e de desenvolvimento, bem como garantir acesso universal às informações, especialmente as 
orçamentárias, nos âmbitos da união, estados e municípios. Esses problemas convivem numa sociedade de grande importância na região, uma sociedade de massas mas ainda com um consumo de massas não muito apreciável, no sentido de que persiste uma grande pobreza. Esses dois últimos pontos significam um condicionamento dos modos de vida das pessoas a uma mídia hipertrofiada onde os desejos de consumo são exponenciados sem a possibilidade de serem satisfeitos, bem como por uma indústria cultural de massa que nega a capacidade de realização individual e pessoal, vale dizer, de liberdade pessoal de pensamento e expressão. Esses sintomas não são só brasileiros, mas foram detectados nas sociedades modernas por inúmeros autores desde Freud . O problema não é só o baixo consumo mas a exacerbação do desejo de consumir o que não se pode, além do fato de que os desejos são massificados rompendo sua característica de individualização e realização pessoal. Isso convive com a violência e inúmeras formas de sociabilidade que ferem idealmente as que deveriam existir numa sociedade ligada por nexos de solidariedade e fechamento das suas feridas históricas. $\mathrm{Na}$ verdade, assiste-se a uma recriação de traços coloniais ininterrupta.

Até aqui falamos sobre a condição dependente e subdesenvolvida de um país que ainda não transitou ao estatuto da nação, tal como compreendido por autores clássicos como Caio Prado Júnior e Celso Furtado. Falamos também da dificuldade da participação pública na democracia brasileira, bem como no emperramento de mecanismos que aproximariam os governos sul-americanos no sentido de criar uma região na América menos heterogênea e desigual. Todavia como relacionar essa discussão com a educação?

Economia e educação se aproximam tradicionalmente na ótica liberal supondo um mercado que tende ao equilíbrio se deixado livre de coerções extraeconômicas, e a partir daí pode se obter um equilíbrio social com distribuição das oportunidades de emprego e renda de forma concorrencial e meritocrática. Esta posição supõe uma apolitização da discussão pretendida na medida em que sua hipótes versa sobre a da obtenção de um ótimo independente de posições de classe e da conversão do estado em um organismo capaz de suprir ou reverter os mecanismos sociais e de mercado que tendam a criar e a reproduzir desigualdades.

A meu ver, entretanto, há necessidade de um projeto político para a economia e a sociedade no Brasil, que ultrapasse os projetos atuais levando à constituição de um capitalismo democrático e popular. Se a história brasileira criou contradições na vida social sob vários ângulos, políticos, raciais, sexuais, religiosos e outros, é necessário pensar em transformar essas contradições em uma ação articulada para uma sociedade solidária e não 
fragmentada e ao mesmo tempo próspera. Algo assim foi tentado com o populismo histórico e especialmente no governo João Goulart, que se transformou numa derrota histórica, que de alguma forma é preciso ainda reverter repensando algum tipo de populismo válido no contexto dos difíceis dias que vivemos.

É preciso, por exemplo, que a Bolsa Escola e o crédito consignado deixem de ser vistos como grandes conquistas e sim como pontos de partida para novas políticas sociais de inclusão, bem como de novas políticas financeiras no país. Essas políticas são apenas transitórias devendo ceder espaço para políticas mais avançadas de educação, saúde, emprego, renda, crescimento econômico, informação e assim por diante. Isso é muito difícil de ser conquistado no Brasil. Mesmo no caso da ciência e tecnologia, crucial para uma política industrial e de desenvolvimento, vemos um impasse. Nele, muitas carreiras superiores terminam estagnadas no Brasil, pela ineficácia de um estado que contemple mais ativamente o desenvolvimento em sentido amplo, o que é coerente com um país no qual a burguesia industrial nunca foi dominante e o estado sempre foi visto pela elite com desconfiança. Basta ver as dificuldades de governo com que se depara a equipe do presidente Lula.

O conjunto da educação não tem, entretanto, por objetivo, o desenvolvimento econômico - escola e trabalho nem sempre andam ou devem andar juntos. A busca, no entanto, deve ser em direção a uma verdadeira cidadania e a conquista da liberdade individual que são a busca central tanto do liberalismo clássico bem como do socialismo. Como entender isso no Brasil de hoje sem usar palavreado oco? Penso que um ponto de partida reside numa pequena menção à palavra "troca". Para Nietzsche a troca é o caráter inicial da justiça através da qual um dá ao outro o que ele quer para receber o desejado. Nesse sentido, uma ação justa e eqüitativa não é necessariamente uma ação altruísta, que pode inibir a autopreservação.

Entretanto, Marx mostrou que uma sociedade na qual seus componentes se convertem em elos de uma divisão social do trabalho que só se socializam na troca, inibe a liberdade pessoal e mina a capacidade de realização individual. Nesse sentido, tem mais apelo ético uma sociedade na qual os produtores sejam diretamente socializados em seu trabalho e não só nele mas em sua expressão pessoal livre, desejada. Se aí não temos uma sociedade altruísta, é duvidoso. Uma sociedade na qual as pessoas possam se desenvolver livremente para si em contato com os outros, respeitando valores tradicionais do humanismo e do cosmopolitismo, é de alguma forma uma sociedade altruísta, capaz de desenvolver o sentido da solidariedade, da fraternidade e da irmandade. Penso que esta é uma pista para pensar a 
questão acima esboçada sobre as relações entre economia, sociedade e educação. Se não pudermos pensar em uma utopia como a de Marx, podemos ao menos pensar em uma sociedade onde se socializem as metas e nexos capazes de erradicar no Brasil a banalizada injustiça social e dar um conteúdo civilizador à nossa economia e às nossas políticas públicas, bem como melhorar nosso papel de aglutinador na nossa região da América e nossa inserção enquanto protagonistas ativos no mundo .

\section{REFERÊNCIAS}

SARTI, F; LAPLANE, M. L. O investimento direto estrangeiro e a internacionalização da economia brasileira nos anos 90. In: LAPLANE, M.; COUTINHO, L.; HIRAKUTA, C. Internacionalização e desenvolvimento da indústria no Brasil. São Paulo: Fundação Editora da UNESP, 2003.

TEIXEIRA, A. C. Até onde vai a participação cidadã? Le Monde Diplomatique Brasil, São Paulo, ano 2, n. 7, fev. 2008.

VENTURA, D. Sociedades efervescentes, governo sem gás - op. cit.

STIEGLER, B. A hiperrmassificação e a destruição do indivíduo - op. cit.

FREUD, S. Escritos sobre a psicologia do inconsciente. Rio de Janeiro: Imago, 2006, v. 1.

MALLORQUIN, C. Celso Furtado: um retrato intelectual. Rio de Janeiro: Contraponto, 2005.

NIETZSCHE, F. Humano, demasiado humano. São Paulo: Companhia de Bolso, 2005.

MARX, K; ENGELS, F. O manifesto comunista. In: TEXTOS. São Paulo: Edições Sociais, 1975. 
